\title{
A new methodology for a detailed investigation of quantized friction in ionic liquids ${ }^{\dagger}$
}

\author{
Romain Lhermerout* and Susan Perkin*
}

Received Date

Accepted Date

DOI: 00.0000/xxxxxxxxxx

\begin{abstract}
When confined at the nanoscale between smooth surfaces, an ionic liquid forms a structured film responding to shear in a quantized way, i.e. with a friction coefficient indexed by the number of layers in the gap. So far, only a few experiments have been performed to study this phenomenon, because of the delicate nature of the measurements. We propose a new methodology to measure friction with a Surface Force Balance, based on the simultaneous application of normal and lateral motions to the surfaces, allowing for a more precise, comprehensive and rapid determination of the friction response. We report on proof-of-concept experiments with an ionic liquid confined between mica surfaces in dry or wet conditions, showing the phenomenon of quantized friction with an unprecedented resolution. First, we show that the variation of the kinetic friction force with the applied load for a given layer is not linear, but can be quantitatively described by two additive contributions that are respectively proportional to the load and to the contact area. Then, we find that humidity improves the resistance of the layers to be squeezed-out and extends the range of loads in which the liquid behaves as a superlubricant, interpreted by an enhanced dissolution of the potassium ions on the mica leading to a larger surface charge. There, we note a liquid-like friction behavior, and observe in certain conditions a clear variation of the kinetic friction force over two decades of shearing velocities, that does not obey a simple Arrhenius dynamics.
\end{abstract}

\section{Introduction}

Lubrication consists in inserting a substance -generally a liquid- ${ }_{22}$ between two solid surfaces in order to produce a controlled and ${ }_{23}$ stable friction. Its study is an old but still active field of research, ${ }_{24}$ because of the complexity of the phenomena at play 112 . As most ${ }_{25}$ real surfaces are rough, the contact between two macroscopic ${ }_{26}$ bodies involve in fact many mesoscopic asperities. A first con- ${ }_{27}$ sequence is that very large pressures, shear stresses and temper- ${ }_{28}$ atures can be reached locally to promote tribological processes ${ }_{29}$ like wear, phase transitions or (electro)chemical reactions, mak- ${ }_{30}$ ing the role of the lubricant really challenging. A second conse- ${ }_{31}$ quence is that the lubricant should act at different scales simulta- ${ }_{32}$ neously: for thick films, friction is governed by continuum hydrodynamics and depends on the lubricant viscosity (hydrodynamic ${ }_{34}$ regime); for thin films, friction is determined by subtle mecha- ${ }_{35}$ nisms at the molecular scale and depends on the lubricant chemi- ${ }_{36}$ cal structure and its interactions with the solid surfaces (boundary ${ }_{37}$ lubrication regime). Ionics liquids, which are pure salts that are ${ }_{38}$ liquid at ambient temperature and pressure, are promising lubri-

Department of Chemistry, Physical and Theoretical Chemistry Laboratory, Univer- 41 sity of Oxford, Oxford OX1 3QZ, UK. E-mail: romain.lhermerout@chem.ox.ac.uk; 42 susan.perkin@chem.ox.ac.uk

$\dagger$ Electronic Supplementary Information (ESI) available. See DOI: ${ }^{43}$

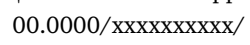

cants thanks to their unique physico-chemical stability ${ }^{3}$. During the last decade, many experiments with a Surface Force Apparatus/Balance (SFA/SFB) or an Atomic Force Microscope (AFM) have been performed to measure the normal interactions on a single asperity across an ionic liquid. They consistently showed the presence of a structural force, i.e. a force profile exhibiting a decaying oscillation, that has been attributed to the ordering of ions in the confined film, with a structure consisting of alternating layers of anions and cations (as sketched in Figure 1(a) 4 $^{4} 12$. Only a few studies have been conducted to measure the friction response in such structured film of ionic liquid, reporting on the phenomenon of "quantized friction", namely the fact that the friction coefficient is indexed by the number of layers composing the film $710 \mid 13$.18. Although the presence of such exotic behavior is now well-established experimentally, the fundamental mechanisms responsible for it are still debated. These outstanding questions motivate further detailed experimental investigations of quantized friction.

In this paper, we present a new methodology to measure friction in the boundary lubrication regime with a SFB. The principle consists in applying normal and lateral motions simultaneously instead of alternatively- to the solid surfaces, allowing for a more precise, comprehensive and rapid determination of the frictionload relationship. First, we validate the method by measuring the 


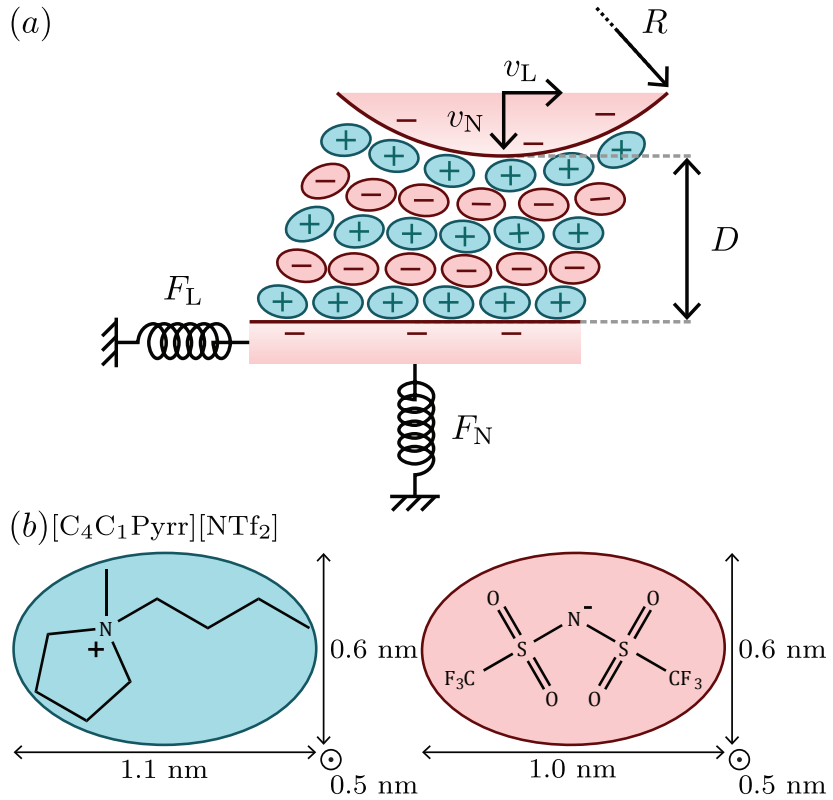

Fig. 1 (a) Schematic of the SFB experiment to measure interactions 89 across a liquid (an ionic liquid in the present case) confined between two 90 mica surfaces. The top surface is moved at normal velocity $v_{\mathrm{N}}$ and lat- ${ }_{91}$ eral velocity $v_{\mathrm{L}}$, the bottom surface is mounted on springs to detect the normal force $F_{\mathrm{N}}$ and the lateral force $F_{\mathrm{L}}$, the apical distance $D$ and the ra- ${ }^{92}$ dius of curvature $R$ are measured by optical interferometry. (b) Chemical ${ }^{93}$ structure and sizes of $\left[\mathrm{C}_{4} \mathrm{C}_{1} \mathrm{Pyrr}\right]\left[\mathrm{NTf}_{2}\right]$. Ion sizes are estimated from ge- 94 ometry, bond lengths and covalent radii, associated with the most stable 95 configuration found by energy minimization (Chem3D 16.0, PerkinElmer ${ }_{96}$ Informatics). phenomenon of quantized friction with an unprecedented resolution, for an ionic liquid confined between mica surfaces. This ${ }^{100}$ allows us to quantitatively explore the relationship between fric- ${ }^{101}$ tion, load and contact area, as well as to elucidate the role of ad- ${ }^{-102}$ hesion. Then, we show that traces of water induce an increase of ${ }^{103}$ the resistance of the layers to be squeezed-out, and an extension ${ }^{104}$ of the range of loads in which the liquid behaves as a superlubri- ${ }^{105}$ cant. There, we note a liquid-like friction behavior and observe ${ }^{100}$ that the kinetic friction force clearly depends on the shearing ve- ${ }^{107}$ locity, for a particular film composition in wet conditions. The dynamics is strongly non-linear, and is interpreted by means of ${ }_{110}^{109}$ different models of friction kinetics.

The paper is organised as follows. In section titled "Materials and Methods", we summarize the general procedure to perform ${ }_{113}^{112}$ a SFB experiment, and we present the new methodology to measure friction. In section titled "Results and Discussion", we describe and interpret the normal and lateral forces measurements ${ }_{116}^{115}$ performed across an ionic liquid, for different conditions of humidity and variable shearing velocities.

\section{Materials and Methods}

\subsection{Surface Force Balance}

The way the Surface Force Balance (SFB) works has been ex-119 plained in details in previous publications 1922 . Here we briefly ${ }_{120}$ recall the principle of the instrument, illustrated in Figure 1(a), 121 and the details particular to the present experiments.
Muscovite mica is cleaved to produce atomically-smooth facets of micrometric thickness and millimetric extension, that are backsilvered and glued onto glass (fused silica) cylindrical (radius $R \sim$ $1 \mathrm{~cm}$ ) lenses with an epoxy resin (EPON 1004, Shell Chemicals). Two surfaces are made with mica of the same thickness, and are arranged in a cross-cylinder geometry. First, calibrations are done in a dry atmosphere, which is achieved by inserting $\mathrm{P}_{2} \mathrm{O}_{5}$, phosphorus pentoxide (Sigma-Aldrich, 99\%), in the chamber and purging the chamber with $\mathrm{N}_{2}$, nitrogen, for about one hour prior to the calibrations. The undeformed mica thickness $e_{\text {mica }, 0}=$ $7.431 \mu \mathrm{m}$ is determined when the surfaces are in direct contact, following a procedure detailed in 23 . Secondly, measurements are performed with an ionic liquid, $\left[\mathrm{C}_{4} \mathrm{C}_{1}\right.$ Pyrr] $\left[\mathrm{NTf}_{2}\right]$, 1-butyl1-methylpyrrolidinium bis [(trifluoromethane)sulfonyl]imide (Iolitec, 99\%), which chemical structure and sizes are indicated in Figure 1 (b) (molar mass $M=422.41 \mathrm{~g} / \mathrm{mol}$, density $\rho=$ $1.405 \mathrm{~g} / \mathrm{mL}$, refractive index $n=1.422$ and dynamic viscosity $\eta=74 \mathrm{mPa}$.s at $25^{\circ} \mathrm{C}^{24}$ ). This liquid is hygroscopic, and we use it either in dry or wet conditions. Dry conditions are achieved by drying the liquid in a Schlenck line at $60^{\circ} \mathrm{C}$ and $5 \times 10^{-3} \mathrm{mbar}$ for $\sim 10$ hours and by inserting it in the chamber just after, which contains $\mathrm{P}_{2} \mathrm{O}_{5}$ and is purged again with $\mathrm{N}_{2}$ for about one hour prior to the measurements. Such procedure is known to produce water content typically $\lesssim 100 \mathrm{ppm}^{11 / 15 / 25}$. Wet conditions are achieved by simply letting the ionic liquid equilibrate with ambient atmosphere during several days before the experiment and by inserting it in the chamber, which does not contain any desiccant and is filled with ambient air. In this case, the water content corresponds to the thermodynamic equilibrium of the ionic liquid with ambient humidity $(\sim 50 \%)$.

White light is passed through the confined medium, interferes in this optical resonator, and is then directed towards a spectrometer and collected by a CCD camera. The analysis of the Fringes of Equal Chromatic Order (FECO) then allows one to deduce the apical distance $D$, the contact radius $a$ (when the surfaces are flattened) and the radius of curvature $R^{26}$. In a separate paper $\frac{23}{23}$, we show that the mica can be significantly compressed and that $D$ incorporates the variations of thicknesses of the mica layers and of the liquid film, i.e the materials separating the two silver mirrors. For small changes of $D$, it is not possible to disentangle the contributions coming from the mica (indentation $2 e_{\text {mica }, 0}-2 e_{\text {mica }}=2 \delta e_{\text {mica }}$, defined positive for compression and negative for dilatation) and the liquid (thickness $D_{\text {liquid }}$ ) with the FECO. In fact, we effectively measure the distance between the silver mirrors $D_{\text {mirrors }}=D_{\text {liquid }}+2 e_{\text {mica }}$, from which we subtract the undeformed mica thickness $2 e_{\text {mica. } 0}$ calibrated in dry atmosphere, to finally obtain:

$$
D=D_{\text {mirrors }}-2 e_{\text {mica }, 0}=D_{\text {liquid }}-2 \delta e_{\text {mica }} \text {. }
$$

$D$ is measured with a precision of $0.02 \mathrm{~nm}$ given by the standard alignment when changing the contact spot 27 . As the glue thickness is heterogeneous, the top mica surface has a different curvature than the bottom glass lens, which has to be measured every time the contact spot is changed. The radius of curvature $R$ as- 
sociated to each measurement is indicated in the figure caption, 179 and is known with an uncertainty of $\sim 0.01 \mathrm{~cm}$ (mainly caused ${ }_{180}$ by the fact that the separation profile between the surfaces is ob-181 served up to a maximum scale $\sim 50 \mathrm{~nm} \ll R \sim 1 \mathrm{~cm}$ ). The contact ${ }_{182}$ radius $a$ is measured with a precision of $0.03 \mu \mathrm{m}$ given by the stan-183 dard deviation of the signal, and an accuracy of $1 \mu \mathrm{m}$ due to the uncertainty on the value of $R$, following a procedure explained in details in 23 .

The top surface can be moved normally with a stepper motor (large displacement range $\sim 10 \mu \mathrm{m}$, poor linearity, mechanical vibrations induced), and also normally and laterally thanks to a ${ }^{185}$ sectored piezoelectric tube (small displacement range $\sim 1 \mu \mathrm{m},{ }^{186}$ good linearity, no measurable mechanical vibrations induced). ${ }^{187}$ For a given run, the velocity $v$ can be determined with a preci- ${ }^{188}$ sion of $\sim 1 \%$. From run to run, this velocity can typically vary ${ }^{189}$ by $\sim 10 \%$ for the same control parameters, because of thermal ${ }^{190}$ drifts. In the following, some graphs result from the superpo- ${ }^{191}$ sition of several runs, that is why the indicated velocities have ${ }^{192}$ to be associated with an error bar of $\sim 10 \%$. The bottom lens ${ }^{193}$ is mounted on two springs: a normal (resp. lateral) spring of ${ }^{194}$ constant $k_{\mathrm{N}}=2670 \pm 84 \mathrm{~N} / \mathrm{m}$ (resp. $\left.k_{\mathrm{L}}=379 \pm 2 \mathrm{~N} / \mathrm{m}\right)$, which ${ }^{195}$ is calibrated before the experiment by measuring its deflection ${ }^{196}$ (resp. its resonance frequency) when adding different masses. ${ }^{197}$ The normal force $F_{\mathrm{N}}$ is deduced from the temporal evolution of the distance $D(t)$ when applying a constant normal velocity $v_{\mathrm{N}}{ }^{198}$ to the top surface, using a procedure that takes into account the ${ }^{199}$ viscous force that is not negligible at large separations (detailed200 in ${ }^{22}$ ). The lateral force $F_{\mathrm{L}}$ is directly measured with a capaci-201 tance probe when applying a constant lateral velocity $v_{\mathrm{L}}$ to the ${ }^{202}$ top surface, with a sensitivity of $\sim 10^{-3} \mathrm{mN}$. In comparison to 203 previous studies performed in our group, the normal spring is ${ }^{204}$ here about 20 times stiffer, in order to apply larger loads (at fixed ${ }^{205}$ displacement range). Together with the stepper motor, it enables ${ }^{206}$ the identification of the first layer consisting of a monolayer of ${ }^{207}$ cations (labelled $i=1$, as sketched in inset of Figure 2(a)), and208 the assessment of the resistance of the liquid to be squeeze-out ${ }^{209}$ under very large pressures. Together with the sectored piezoelec-210 tric tube, it enables one to reach the first layer of ions and so to ${ }^{211}$ explore the whole friction-load relationship with the new method-212 ology (procedure detailed in next subsection). This comes with $\mathrm{a}^{213}$ price in terms of sensitivity limit for the normal force, $\sim 10^{-2} \mathrm{mN},{ }^{214}$ which does not allow the detection of the anomalously long-range electrostatic force that has been observed with concentrated elec-215 trolytes $11 / 222528$-34.

The SFB is therefore a tool of choice to study the molecular 217 mechanisms of friction: the two atomically-smooth surfaces are in 218 contact on a single asperity (pure boundary lubrication regime),219 the apical distance $D$ is measured with a resolution better than 220 the molecular scale, and the geometry can be characterized in-221 situ (radius of curvature $R$, contact radius $a$ ). In the literature, the 222 measured normal force $F_{\mathrm{N}}$ is generally rescaled by the radius of ${ }_{223}$ curvature $R$ to compute an equivalent surface energy $F_{\mathrm{N}} / R$, con-224 sidering that mechanical deformations are negligible and that the 225 Derjaguin approximation applies 19 . In the opposite case when 226 the surfaces are strongly flattened, it is reasonable to assume that 227 the total force $F_{\mathrm{N}}$ is mainly due to the interaction ion the flattened 228 region, and so to rescale it by the contact area $\pi a^{2}$ to compute the local pressure $F_{\mathrm{N}} /\left(\pi a^{2}\right)$. In this study, we explore a broad range of situations from no deformation to strong deformations, that is why we have chosen to simply use the force $F$ without any rescaling in the plots.

\subsection{New Methodology for friction measurement}

So far, friction measurements with the SFA/SFB or the AFM were performed by applying normal and lateral motions alternatively: the surfaces were approached/retracted at a given distance under a given load, then the liquid was sheared, and so on $13 / 15$. The principle of the new methodology consists in applying normal and lateral motions simultaneously to the surfaces: if the approach/retraction rate is much smaller than the shearing rate (typically $v_{\mathrm{N}} \sim 1 \mathrm{~nm} / \mathrm{s} \ll v_{\mathrm{L}} \sim 100 \mathrm{~nm} / \mathrm{s}$ ), the distance and the load can be considered as constant within one shearing period. Such procedure has been already used by Hoth et al. ${ }^{10}$ with a AFM but without analyzing the data to deduce the friction-load relationship, and by Crespo et al..$^{35}$ and us ${ }^{36}$ with a SFA but not in the context of a structured liquid film.

Simply imposing a continuous instead of stepped motion in the normal direction potentially offers significant advantages. (i) The measurements are more precise (i.e. less scattered), because less time is left for the system to drift between points (inevitable longterm drifts due to thermal expansion and creep of the mechanical parts), which is necessary to investigate quantitatively the relationship between friction, load and contact area, and to finely test proposed models. (ii) The method allows for a more comprehensive exploration of friction-load relationship, in particular in the vicinity of spring instabilities (jump-out on retraction, jump-in on approach), which is crucial to elucidate the role of adhesion on friction, and to better understand the film dynamics during the squeeze-out transition. (iii) The whole friction phenomenology can be acquired more rapidly (in typically $\sim 1 \mathrm{~h}$ instead of $\sim 10 \mathrm{~h}$ to probe all the layers of a structured film), which is convenient to efficiently probe various physico-chemical systems and to assess the reproducibility of the measurements.

However, a careful implementation of the technique is required to avoid possible artefacts. First, the liquid structure itself can be affected by the shearing motion, a phenomenon that has been qualitatively interpreted as a combing of long-chain molecules $37+42$. Secondly, the friction force can be reduced by mechanical vibrations (potentially induced by the simultaneous normal motion), which qualitatively act as an effective temperature that helps to overcome the energy barrier associated with the molecules passing each other $43 / 48$. For the experiments reported in this paper, we ruled out these artefacts by systematically checking that the normal force profile is the same with a zero and non-zero lateral velocity (see Supplementary Figure 1), and that the friction-load relationship is the same with a zero and non-zero normal velocity (see Supplementary Figure 2). 

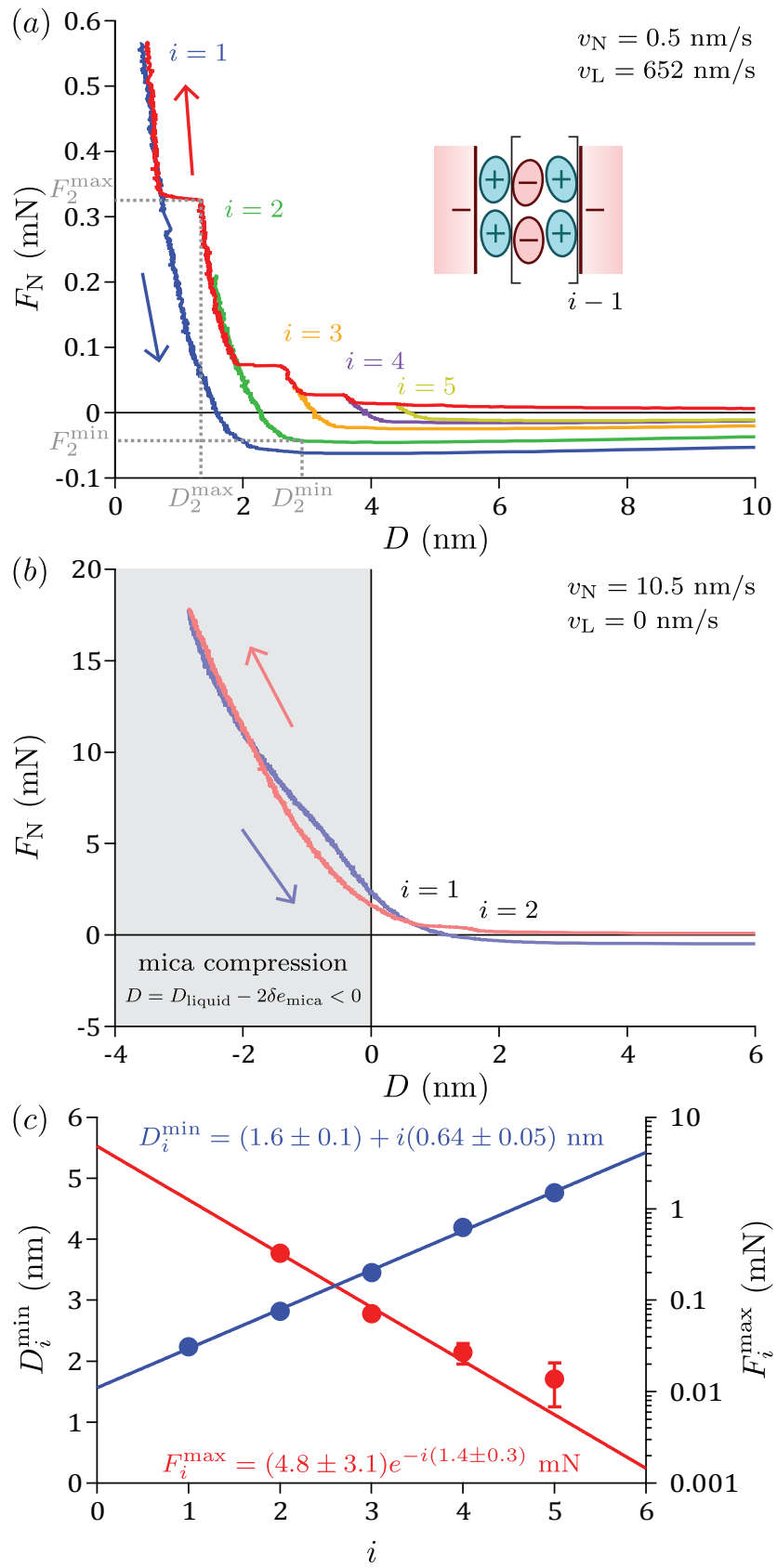

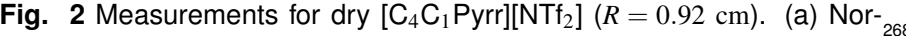
mal force profile when moving the top surface with the piezoelectric tube at a normal velocity $v_{\mathrm{N}}=0.5 \mathrm{~nm} / \mathrm{s}$ and a lateral velocity $v_{\mathrm{L}}=652 \mathrm{~nm} / \mathrm{s}$, ${ }^{269}$ showing structuring with 5 distinguishable layers labeled by $i$. For clar-270 ity, only the full approach is shown (in red), together with retractions 271 from layers $i=1$ (in blue), $i=2$ (in green), $i=3$ (in orange), $i=4\left(\mathrm{in}_{272}\right.$ purple), $i=5$ (in yellow). Inset: proposed structure of alternating layers of cations and anions. (b) Normal force profile when approaching (in faded red) or retracting (in faded blue) the top surface with the stepper motor at $v_{\mathrm{N}}=10.5 \mathrm{~nm} / \mathrm{s}$. Negative distances $D$ are reached at large loads, because the compression of mica exceeds the liquid thickness:273 $D=D_{\text {liquid }}-2 \delta e_{\text {mica }}<023$. The curves measured on approach and re-274 traction in layer $i=1$ are not perfectly superimposed because of mechanical imperfections of the set-up (poor linearity of the stepper motor, tiny rotations of the solids, etc.). (c) Distances $D_{i}^{\mathrm{min}}$ at the points of minimum ${ }^{276}$ force, as a function of the layer index $i$, in lin-lin representation (in blue); $; 27$ forces $F_{i}^{\max }$ at the points of maximum force, as a function of the layer278 index $i$, in log-lin representation (in red). Straight lines are the corre- 279 sponding linear and exponential fits (equations 2 and 3 .

\section{Results and Discussion}

\subsection{Normal force}

We begin with presenting measurements of the normal interaction force. Figure 2(a) shows the normal force profile obtained when moving the top surface with the piezoelectric tube at a normal velocity $v_{\mathrm{N}}=0.5 \mathrm{~nm} / \mathrm{s}$ and a lateral velocity $v_{\mathrm{L}}=652 \mathrm{~nm} / \mathrm{s}$ across dry $\left[\mathrm{C}_{4} \mathrm{C}_{1}\right.$ Pyrr $]\left[\mathrm{NTf}_{2}\right]$. When the ionic liquid is confined at the nanoscale, a structural force profile is observed, with five distinguishable layers labeled by $i$. Such structural force has been observed many times with ionic liquids, and attributed to the ordering of ions in the film, with a structure consisting of alternating layers of anions and cations (as sketched in inset) 4 .12. Because of the spring instability, the surfaces experience a jump-in on approach every time a layer is squeezed-out, and a jump-out on retraction from a given layer. Therefore several runs were in fact necessary for the most comprehensive exploration of the force profile. Supplementary Figure 3 shows the force profiles measured when approaching the top surface up to a given layer and retracting from this layer. From run to run, the whole force profile randomly shifts laterally by a fraction of nanometer. As the jump-in distances and the forces are reproducible, we consider that these shifts are non physical, but result from imperfections of the set-up like tiny rotations of the solids. That is why we have shifted manually the force profiles such that all the approaches are superimposed on the approach up to layer $i=1$ (in red). Figure 2(a) shows the resulting force profile, with for clarity only the approach up to layer $i=1$ (in red), and the retractions from the different layers ( $i=1$ in blue, $i=2$ in green, $i=3$ in orange, $i=4$ in purple, $i=5$ in yellow).

In a separate paper ${ }^{23}$, we show that the oscillation due to local variations of liquid density in the confined film is in general convoluted with the mechanical response of the confining solids. For the system studied here, we found that (i) mica compression dominates liquid compression, i.e. the change of $D$ within each layer is mainly due to the indentation of mica; (ii) contact mechanics is well described by the Derjaguin-Muller-Toporov (DMT) model 1949,52 , in particular the indentation of the solids is zero at the minimum force (jump-out point) and continuously increases up to the maximum force (jump-in point). For each layer $i$, we have measured the distance $D_{i}^{\text {min }}$ at the point of minimum force (jump-out, as indicated in Figure 2(a) for $i=2$ ), which does not include any influence of the mica compression. The variation of the distance $D_{i}^{\mathrm{min}}$ with the layer index $i$ is shown in Figure 2(c), and exhibits a good linearity. It is fitted with the relation:

$$
D_{i}^{\min }=D_{0}^{\min }+i \lambda^{\min },
$$

where the slope $\lambda^{\mathrm{min}}=0.64 \pm 0.05 \mathrm{~nm}$ represents the mean layer thickness and the intersect $D_{0}^{\min }=1.6 \pm 0.1 \mathrm{~nm}$ corresponds to the position of the extrapolated layer $i=0$. Another method consists in measuring the average jump-in distance, supposing an unchanged mica compression and a fast viscous relaxation during the squeeze-out events, and providing a consistent value of $0.64 \pm 0.01 \mathrm{~nm}$ for the mean layer thickness. Interestingly, this value is smaller than the mean ion pair diameter of $0.79 \mathrm{~nm}$ (given 
by $\left(\frac{M}{\rho N_{\mathrm{A}}}\right)^{1 / 3}$ with $M$ the molar mass of the ionic liquid, $\rho$ its bulk density and $N_{\mathrm{A}}$ the Avogadro's number ${ }^{\sqrt{4}}$ ), perhaps suggesting a denser packing of ions in confinement than in the bulk. However, our value is also smaller than the previous measurements performed with the same ionic liquid, reporting a mean layer thickness of $0.80 \pm 0.04 \mathrm{~nm}$ between two mica surfaces with a $\mathrm{SFB}^{53}$ and $0.79 \mathrm{~nm}$ between a mica surface and a $\mathrm{Si}_{3} \mathrm{~N}_{4}$ tip with an $\mathrm{AFM}^{54}$. A possible explanation for this difference is the inherent contribution from viscosity to the force profile, in particular in vicinity to a spring instability. For the method using the distances $D_{i}^{\text {min }}$ at the points of minimum force (giving a mean layer thickness of $0.64 \pm 0.05 \mathrm{~nm}$ ), viscosity tends to move the minima towards larger distances, even more than adhesion is larger (i.e. smaller layer index $i$ ). For the method using the jump-in distances (giving a mean layer thickness of $0.64 \pm 0.01 \mathrm{~nm}$ ), viscosity tends to reduce the size of the jumps. In both cases, viscous effects possibly lead to an underestimation of the mean layer thickness. Previous studies may be less affected by viscosity, as retractions were performed by slow steps in the SFB study ${ }^{53}$ (with similar radius of curvature), and the radius of curvature was six orders of magnitude smaller in the AFM study ${ }^{54}$ (with a velocity less than an order of magnitude larger). Therefore, applying a stepped motion is preferable to a continuous motion in order to accurately $y_{3 з 3}$ determine the mean layer thickness.

An important aspect to interpret the structural force profiles is 335 to identify the composition of the layers. As the period is similar 336 to the mean ion pair diameter, it is qualitatively considered that 337 one squeeze-out event corresponds to the squeeze-out of an elec-3з8 troneutral "slab" of one cation layer and one anion layer. In the ззя case of negatively charged surfaces, the first layer $(i=1)$ is then 340 assumed to be composed of a monolayer of cations (as sketched in 341 inset of Figure 2(a)). Direct solid-solid contact is never reached, 342 because of the strong electrostatic attraction between the cations 343 and the negatively charged surfaces. For our experiment, one can 344 ask whether we really reach this single layer of cations within 345 the explored range of loads. The position of the first layer at 346 the point of minimum force (including no indentation of the sur-347 faces) is $D_{1}^{\min }=2.2 \pm 1.0 \mathrm{~nm}$, a bit larger than the cation sizes 348 (given in Figure 1(b)). However, the measurement of the abso-349 lute distance $D$ depends on many delicate steps (alignment of the 350 optics, calibration of the mica thickness in dry atmosphere, choice 351 of a particular run to shift the force profiles laterally), and deduc-352 ing the thickness of the monolayer from the cation sizes requires 353 to know their conformations, making accurate comparisons dif-354 ficult. For each layer $i$, we have measured the force $F_{i}^{\max }$ at the 355 point of maximum force (jump-in, as indicated in Figure 2(a) for 356 $i=2$ ). The variation of the distance $F_{i}^{\max }$ with the layer index $i$ is shown in Figure 2(c) in log-lin representation, and exhibits $\mathrm{a}_{357}$ good linearity. It is fitted with the relation:

$$
F_{i}^{\max }=F_{0}^{\max } \exp \left(-i \frac{\lambda^{\max }}{\zeta^{\max }}\right),
$$

where the slope gives access to the ratio $\frac{\lambda^{\max }}{\zeta^{\max }}=1.4 \pm 0.3$ of the ${ }_{362}$ period of the oscillation on the decay length (i.e. typical dis-363 tance from a surface on which the oscillations of local liquid den-364

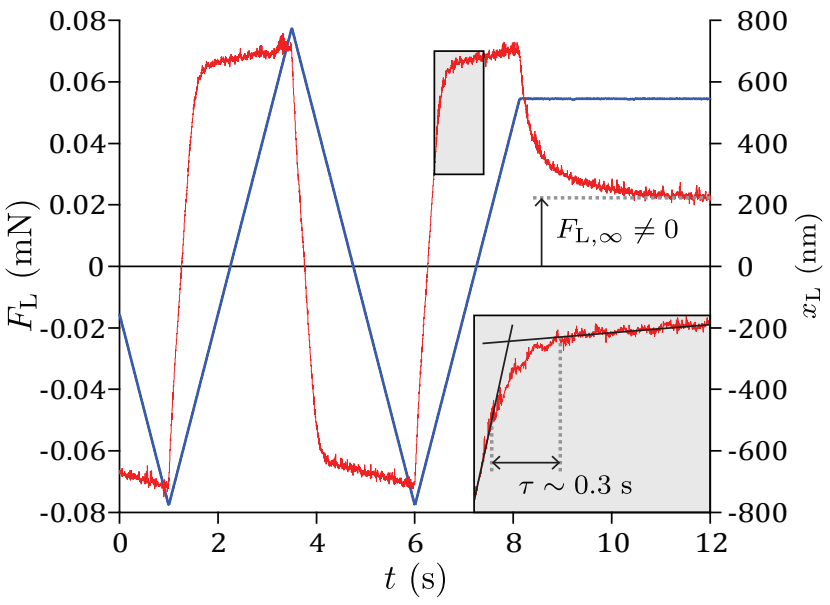

Fig. 3 Measurements for wet $\left[\mathrm{C}_{4} \mathrm{C}_{1}\right.$ Pyrr] $\left[\mathrm{NTf}_{2}\right](R=1.45 \mathrm{~cm})$, at fixed load $F_{\mathrm{N}}=2.79 \mathrm{mN}$, distance $D=-1.05 \mathrm{~nm}$ (where $D=D_{\text {liquid }}-2 \delta e_{\text {mica }}<$ 0 ) and contact radius $a=12.86 \mu \mathrm{m}$ in layer $i=2$. Temporal evolutions of the lateral displacement $x_{\mathrm{L}}$ and lateral force $F_{\mathrm{L}}$, showing a liquid-like friction behavior. Inset: zoom on a part of the signal, delimited by a gray rectangle in the main graph. The tiny oscillation is due to the resonance of the mass-spring system at $\sim 20 \mathrm{~Hz}$.

sity are damped), and the intersect corresponds to the amplitude $F_{0}^{\max }=4.8 \pm 3.1 \mathrm{mN}$ of the extrapolated layer $i=0$. If we extrapolate this fit to the layer $i=1$, it predicts that the next squeeze-out event would take place at a force $F_{\mathrm{N}}=1.3 \pm 0.6 \mathrm{mN}$. Figure 2(b) shows the normal force profile obtained when approaching (in faded red) then retracting (in faded blue) the top surface with the stepper motor at a velocity $v_{\mathrm{N}}=10.5 \mathrm{~nm} / \mathrm{s}$. We do not observe any additional jump-in for a force up to $F_{\mathrm{N}}=17.80 \mathrm{mN}$. Thus, we think that the layer seen at the maximum load is indeed composed of a single layer of cations, and we identify it as $i=1$. Note that negative distances $D$ are reached at large loads, because the compression of mica exceeds the liquid thickness: $D=D_{\text {liquid }}-2 \delta e_{\text {mica }}<0^{23}$.

On a practical point of view, we observe that applying a maximum load $F_{\mathrm{N}}=17.80 \mathrm{mN}$ does not lead to a complete squeeze-out of the confined liquid film, even if the confining solids are already strongly deformed: mica is compressed by a few nanometers and the surfaces are flattened on a contact radius $a=21.61 \mu \mathrm{m}$, corresponding to a pressure $\sim F_{\mathrm{N}} /\left(\pi a^{2}\right) \sim 12 \mathrm{MPa}$. The first layer, which consists of a monolayer of cations, is so strongly bounded to the oppositely charged mica surfaces that it is never squeezedout. This is a very good property for a potential lubricant, because keeping the solid surfaces apart is an efficient way to prevent wear.

\subsection{Lateral force}

In this subsection, we identify the nature of the friction response, by analyzing the shape of the lateral force when the liquid film is sheared under constant conditions in the normal direction. Figure 3 shows the temporal evolutions of the lateral displacement $x_{\mathrm{L}}$ and lateral force $F_{\mathrm{L}}$ for wet $\left[\mathrm{C}_{4} \mathrm{C}_{1}\right.$ Pyrr] $\left[\mathrm{NTf}_{2}\right]$, at fixed load $F_{\mathrm{N}}=2.79 \mathrm{mN}$, distance $D=-1.05 \mathrm{~nm}$ (where $D=D_{\text {liquid }}-$ $2 \delta e_{\text {mica }}<0$ ) and contact radius $a=12.86 \mu \mathrm{m}$ in layer $i=2$. When 
starting to apply a constant lateral velocity $v_{\mathrm{L}}=639 \mathrm{~nm} / \mathrm{s}$, the 419 lateral force exhibits first a linear variation of slope $k_{\mathrm{L}} \times v_{\mathrm{L}}$, then ${ }_{420}$ a relaxation with a typical timescale $\tau \sim 0.3 \mathrm{~s}$, there a smooth-421 sliding creep of amplitude $\sim 0.07 \mathrm{mN}$. When the direction of the 422 motion is reversed, the lateral force responds in a symmetric man-423 ner with respect to the horizontal axis. If the lateral motion is 424 suddenly stopped, the lateral force exhibits a relaxation with $\mathrm{a}_{425}$ similar timescale $\tau$ towards an amplitude $F_{\mathrm{L}, \infty} \neq 0$.

To interpret the observed friction behavior, we first recall the ${ }^{427}$ response of a simple viscous liquid (bulk viscosity $\eta=74 \mathrm{mPa} . \mathrm{s}$ ) ${ }^{428}$ sheared between two planar surfaces (liquid thickness $D_{\text {liquid }} \sim 429$ $1 \mathrm{~nm}$, area $\mathscr{A} \sim \pi a^{2} \sim 523 \mu \mathrm{m}^{2}$ ), the top one being moved at a ${ }^{430}$ lateral velocity $v_{\mathrm{L}}=639 \mathrm{~nm} / \mathrm{s}$ and the bottom one being attached ${ }^{431}$ to a lateral spring of stiffness $k_{\mathrm{L}}=379 \mathrm{~N} / \mathrm{m}^{20137}$. For a charge-432 less, Newtonian liquid in an incompressible and laminar flow be-433 tween undeformable surfaces with a no-slip boundary condition, ${ }^{434}$ the force opposing the motion is purely viscous and results from ${ }^{435}$ the Couette flow in the gap. If the inertial term is negligible in the ${ }^{436}$ equation of motion for the bottom surface, the temporal evolution ${ }^{437}$ of the lateral force is given by the balance of the viscous force and 438 the restoring spring force. When starting to apply a constant lat-439 eral velocity $v_{\mathrm{L}}=639 \mathrm{~nm} / \mathrm{s}$, classical hydrodynamics predicts that ${ }^{440}$ the lateral force exhibits first a linear variation of slope $k_{\mathrm{L}} \times v_{\mathrm{L}}{ }^{441}$ then an exponential relaxation with a timescale $\frac{\mathscr{A} \eta}{k_{\mathrm{L}} D_{\text {liquid }}} \sim 10^{-4} \mathrm{~s},{ }^{442}$ there a smooth-sliding plateau of amplitude $\frac{\mathscr{A} \eta \nu_{\mathrm{L}}}{D_{\text {liquid }}} \sim 2 \cdot 10^{-5} \mathrm{mN}{ }^{443}$ When the direction of the motion is reversed, the lateral force re ${ }^{444}$ sponds in a symmetric manner with respect to the horizontal axis. ${ }^{445}$ If the lateral motion is suddenly stopped, the lateral force exhibits ${ }^{446}$ an exponential relaxation with the same timescale towards a zero ${ }^{447}$ amplitude. Therefore, the phenomenology obtained in our ex- ${ }^{448}$ periment is qualitatively similar to the one expected for a simple ${ }^{449}$ viscous liquid, but with three important differences: (i) the forces ${ }^{450}$ and timescales involved are more than three orders of magnitude ${ }^{451}$ larger, (ii) there is creep instead of a plateau, (iii) a non-zero force ${ }^{452}$ is sustained after stopping the motion. That is why the response ${ }^{453}$ measured here is identified as a liquid-like friction behavior ${ }^{37}$. $\operatorname{In}^{454}$ past experiments with the same ionic liquid a friction response ${ }^{455}$ with features typical of solid-like behavior has been observed. $\operatorname{In}^{456}$ the Supplementary Material we discuss in detail the possible ori- ${ }^{457}$ gin of this difference, and conclude that relative mica orientation ${ }^{458}$ (twist angle) is most likely to be the underlying cause.

\subsection{Friction-Load relationship}

In this subsection, we use the new methodology to explore the ${ }_{463}$ friction-load relationship for dry $\left[\mathrm{C}_{4} \mathrm{C}_{1} \mathrm{Pyrr}\right]\left[\mathrm{NTf}_{2}\right]$. Figure $4(\mathrm{a})_{464}$ shows the temporal evolutions of the apical distance $D$ and lat-465 eral force $F_{\mathrm{L}}$, when moving the top surface with the piezoelec-466 tric tube at a normal velocity $v_{\mathrm{N}}=0.5 \mathrm{~nm} / \mathrm{s}$ and a lateral veloc-467 ity $v_{\mathrm{L}}=652 \mathrm{~nm} / \mathrm{s}$. The amplitude of the lateral force is below ${ }_{468}$ the sensitivity limit of $\sim 10^{-3} \mathrm{mN}$ before reaching layer $i=2,469$ then very small but discernible in this layer, and finally larger in 470 layer $i=1$. In the inset of Figure 4(a) is plotted the variation 471 of the lateral force during the squeeze-out transition from layer 472 $i=2$ to layer $i=1$, a measurement that is possible with the new 473 methodology. The apical distance varies by $\sim 0.64 \mathrm{~nm}$ in $\sim 10 \mathrm{~s}, 474$ during which about four shearing cycles are performed. In this particular case, we are in fact probing the friction response of a transient film configuration, integrated over a time $\sim 2.5 \mathrm{~s}$. The amplitude of the lateral force increases continuously during the squeeze-out transition, showing that an heterogeneous film composed of a mixture of $i=2$ and $i=1$ areas gives a friction response that is intermediate between the responses of homogeneous $i=2$ or $i=1$ films.

To analyze quantitatively the large amount of data generated by this new methodology, we have written a simple code. For each shearing period, it automatically extracts the average lateral force during the creep stage, identified as the kinetic friction force $F_{\mathrm{L}, \mathrm{k}}$, as well as the average load $F_{\mathrm{N}}$, apical distance $D$ and contact radius $a$. We have done this for all the runs that were necessary for the most comprehensive exploration of the structural force profile (see for example Supplementary Figure 4, that shows the full temporal evolutions of the apical distance $D$ and lateral force $F_{\mathrm{L}}$ during the approach up to layer $i=1$ and the retraction from this layer). Figure 4 (b) shows the kinetic friction force $F_{\mathrm{L}, \mathrm{k}}$ as a function of the load $F_{\mathrm{N}}$, when moving the top surface with the piezoelectric tube at a normal velocity $v_{\mathrm{N}}=0.5 \mathrm{~nm} / \mathrm{s}$ and a lateral velocity $v_{\mathrm{L}}=652 \mathrm{~nm} / \mathrm{s}$. The friction coefficient -evaluated as the slope in this friction-load representation- is clearly indexed by the number of ions composing the liquid film, which is the signature of the quantized friction phenomenon. This implies that friction is a multi-valued function of the load. In layer $i=2$ (retraction branch in green), the friction coefficient is $\mu_{2}=0.0064 \pm 0.0006$, i.e. the film composed of two cations layers plus one anions layer behaves as a superlubricant (conventionally defined by a kinetic friction coefficient $<0.01^{2}$ ). In layer $i=1$ (retraction branch in blue), the friction coefficient is $\mu_{1}=0.210 \pm 0.003$ (almost two orders of magnitude larger!), i.e. the film composed of a monolayer of cations behaves as a poor lubricant. The transition between the two regimes happens at a load $F_{\mathrm{N}}=0.33 \mathrm{mN}$, corresponding to a pressure $\sim F_{\mathrm{N}} /\left(\pi a^{2}\right) \sim 2 \mathrm{MPa}$ (given a contact radius $a=6.45 \mu \mathrm{m}$ ).

In comparison to previous studies, the new methodology provides much less scattered data points. This allows us to quantitatively tests different empirical laws of friction, that we briefly recall in the following. For smooth adhering surfaces, it has been argued that the friction force $F_{\mathrm{L}, \mathrm{k}}$ should increase proportionally with the load $F_{\mathrm{N}}$, i.e. $F_{\mathrm{L}, \mathrm{k}}=\mu\left(F_{\mathrm{N}}-F^{\text {min }}\right)$ (with $\mu$ the friction coefficient and $F^{\min }$ the adhesion force), due to the increase of the pressure in the film -the adhesion acting as an internal pressure-55-58. It has also been suggested that the friction force $F_{\mathrm{L}, \mathrm{k}}$ should increase proportionally with the contact area $\mathscr{A}$, i.e. $F_{\mathrm{L}, \mathrm{k}}=\sigma_{\mathrm{c}} \mathscr{A}$ (with $\sigma_{\mathrm{c}}$ the critical shear stress), due to the increase of the surface on which shear stress is integrated $52[59-63$. More generally, it has been proposed that friction comes from these two contributions, i.e. $F_{\mathrm{L}, \mathrm{k}}=\mu F_{\mathrm{N}}+\sigma_{\mathrm{c}} \mathscr{A} / 64$. For the system studied here, we show in a separate paper ${ }^{23}$ that contact mechanics is well described by the Derjaguin-Muller-Toporov (DMT) model 19449:52. The relation between the contact area and the load is $\mathscr{A}=\pi\left(\frac{R}{R}\right)^{2 / 3}\left(F_{\mathrm{N}}-F^{\mathrm{min}}\right)^{2 / 3}$, with $R$ the radius of curvature and $K=16.7 \pm 0.5 \mathrm{GPa}$ the fitted effective elastic modulus -the adhesion again acting as an internal pressure-. Finally, we 

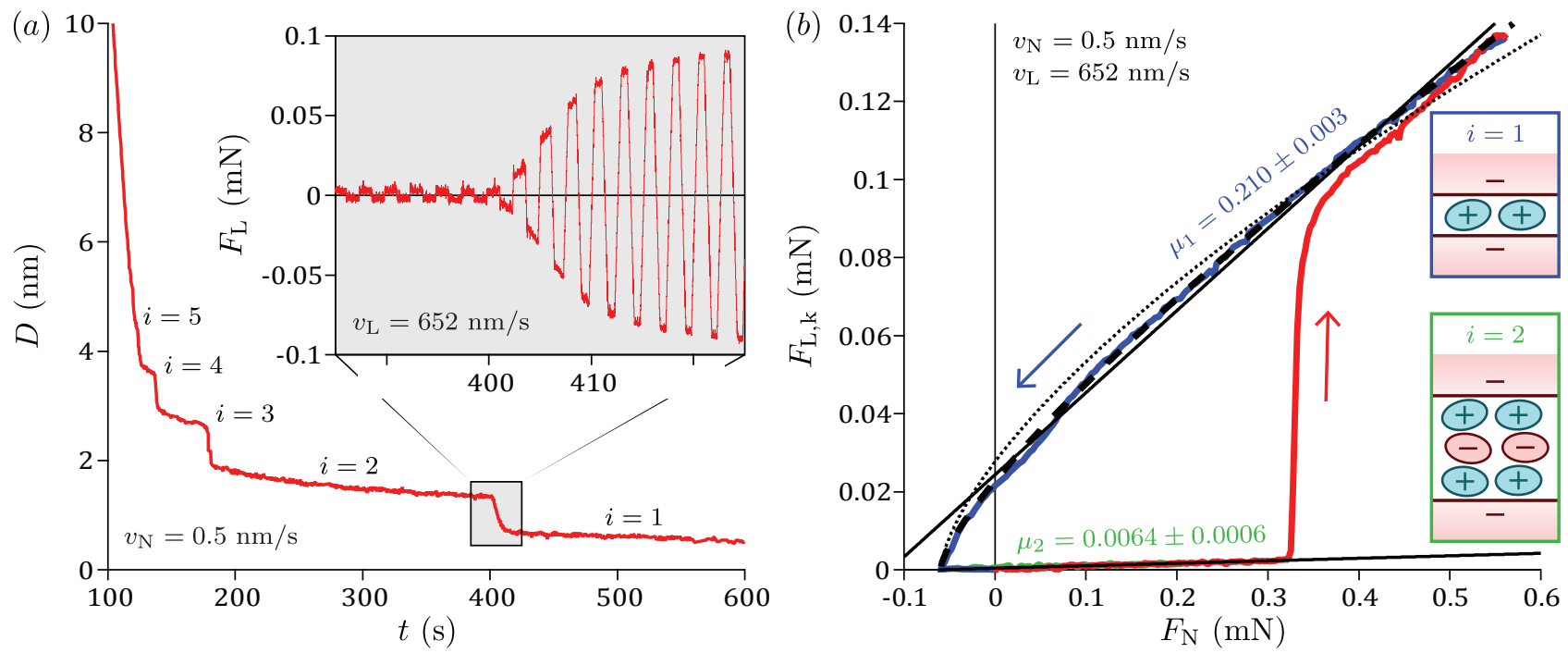

Fig. 4 Measurements for dry $\left[\mathrm{C}_{4} \mathrm{C}_{1}\right.$ Pyrr] $\left[\mathrm{NTf}_{2}\right](R=0.92 \mathrm{~cm})$, when moving the top surface with the piezoelectric tube at a normal velocity $v_{\mathrm{N}}=0.5 \mathrm{~nm} / \mathrm{s}$ and a lateral velocity $v_{\mathrm{L}}=652 \mathrm{~nm} / \mathrm{s}$. (a) Temporal evolution of the apical distance $D$ on full approach. The inset shows the temporal evolution of the lateral force $F_{\mathrm{L}}$ during the squeeze-out transition from layer $i=2$ to layer $i=1$. (b) Kinetic friction $F_{\mathrm{L}, \mathrm{k}}$ as a function of load $F_{\mathrm{N}}$ on full approach (in red) then retraction from layer $i=1$ (in blue). Friction is above the sensitivity limit for the layers $i=1$ and $i=2$ (proposed film structures in insets). Straight lines are fits with the left-hand term of equation 4 with $\left\{\mu_{1}=0.210 \pm 0.003, F_{1}^{\mathrm{min}}=-0.12 \pm 0.01 \mathrm{mN}\right\}$ and $\left\{\mu_{2}=0.0064 \pm 0.0006, F_{2}^{\mathrm{min}}=-0.062 \pm 0.008 \mathrm{mN}\right\}$. The dotted line is a fit for layer $i=1$ with the right-hand term of equation 4 with $\left\{\sigma_{\mathrm{c}, 1}=857 \pm 6 \mathrm{kPa}, F_{1}^{\min }=-0.06 \mathrm{mN}\right\}$. The dashed line is a fit for layer $i=1$ with the whole equation 4 with $\left\{\mu_{1}=0.092 \pm 0.004, \sigma_{\mathrm{c}, 1}=529 \pm 13 \mathrm{kPa}, F_{1}^{\mathrm{min}}=-0.06 \mathrm{mN}\right\}$.

fit the friction-load relationship in layer $i=1$ with the following $5_{502}$ empirical law:

$$
F_{\mathrm{L}, \mathrm{k}}=\mu_{i} \times\left(F_{\mathrm{N}}-F_{i}^{\min }\right)+\sigma_{\mathrm{c}, \mathrm{i}} \times \pi\left(\frac{R}{K}\right)^{2 / 3}\left(F_{\mathrm{N}}-F_{i}^{\min }\right)^{2 / 3},
$$

where $\mu_{i}, \sigma_{\mathrm{c}, \mathrm{i}}$ and $F_{i}^{\min }$ are respectively the friction coefficient, ${ }_{509}$ critical shear stress and adhesion force associated with layer $i_{510}$ This equation gives $F_{\mathrm{L}, \mathrm{k}}=0$ at $F_{\mathrm{N}}=F_{i}^{\text {min }}$, which is in agreement ${ }_{511}$ with our systematic observation that the friction force goes to zero at the jump-out point. If we suppose first that friction is purely ${ }_{513}$ load-controlled and we fit with the left-hand term of equation $4_{514}$ only (straight line in Figure $4(\mathrm{~b})$ ), we get $\left\{\mu_{1}=0.210 \pm 0.003\right.$, $\left.F_{1}^{\min }=-0.12 \pm 0.01 \mathrm{mN}\right\}$ (two free parameters). The fit is clearly not satisfactory and overestimate the adhesion force (compared ${ }_{517}$ to the directly measured $F_{1}^{\mathrm{min}}=-0.06 \mathrm{mN}$ ), because it does not ${ }_{518}$ describe the significant concave curvature that is observed experi- ${ }_{519}$ mentally. If we suppose on the contrary that friction is purely contact area-controlled and we fit with the right-hand term of equation 4 only (dotted line in Figure $4(\mathrm{~b})$ ), we get $\left\{\sigma_{\mathrm{c}, 1}=857 \pm 6 \mathrm{kPa}\right.$, $\left.F_{1}^{\min }=-0.06 \mathrm{mN}\right\}$ (one free parameter, the adhesion force being ${ }^{521}$ fixed). The fit is much better in the vicinity of the adhesion min-522 imum, but now overestimates the concavity of the curve. In fact,523 the experimental data lie in between the two previous fits, and if f $_{54}$ we fit with the full equation 4 (dashed line in Figure 4(b)), we ob-525 tain a very good fit with $\left\{\mu_{1}=0.092 \pm 0.004, \sigma_{\mathrm{c}, 1}=529 \pm 13 \mathrm{kPa}, 526\right.$ $\left.F_{1}^{\mathrm{min}}=-0.06 \mathrm{mN}\right\}$ (two free parameters, the adhesion force being ${ }_{527}$ fixed).

To summarize, the measured friction-load relationship can be 529 described quantitatively with an empirical law, providing that two530 additive contributions are included, the first proportional the load531 and the second proportional to the contact area. In the previous experimental studies of quantized friction across ionic liquids, the friction-load relationship was found to be compatible with a linear variation (i.e. a load-controlled friction), given the scattering on the data points $\frac{13 \mid 15}{}$. It is thanks to the new methodology that we are able to measure the friction-load relationship with an unprecedented resolution, and to quantitatively test the different empirical laws of friction. This is crucial not only for a better understanding of the physics of friction in general, but also to extract quantities $\mu$ and $\sigma_{\mathrm{c}}$ that are intrinsic to the physico-chemical system used and not affected by the particular geometry of the experiment. Unfortunately, such high-resolution measurements are not always possible, for example when friction is small or varies slowly, or cannot be measured on a wide range of loads (like for layer $i=2$ in Figure 4(b)). However, we note that the different fits in layer $i=1$ provide friction coefficients of same order of magnitude. That is why we have decided to fit linearly the friction-load relationships measured with a low resolution, as a semi-quantitative evaluation of the lubrication performances.

\subsection{Effect of humidity}

In this subsection, we present an experiment performed with wet $\left[\mathrm{C}_{4} \mathrm{C}_{1}\right.$ Pyrr $]\left[\mathrm{NTf}_{2}\right]$, illustrating the versatility and the efficiency of the new methodology. The measurements, shown in Figure 5, are qualitatively similar to the dry case, in the sense that we also observe a structural force profile, a liquid-like friction behavior, and a quantized friction-load relationship. But important differences emerge when comparing the results quantitatively.

Figures 5(a) and 5(b) show the normal force profile obtained when moving the top surface normally with the piezoelectric tube at $v_{\mathrm{N}}=0.5 \mathrm{~nm} / \mathrm{s}$ or with the stepper motor at $v_{\mathrm{N}}=3.4 \mathrm{~nm} / \mathrm{s}$ 

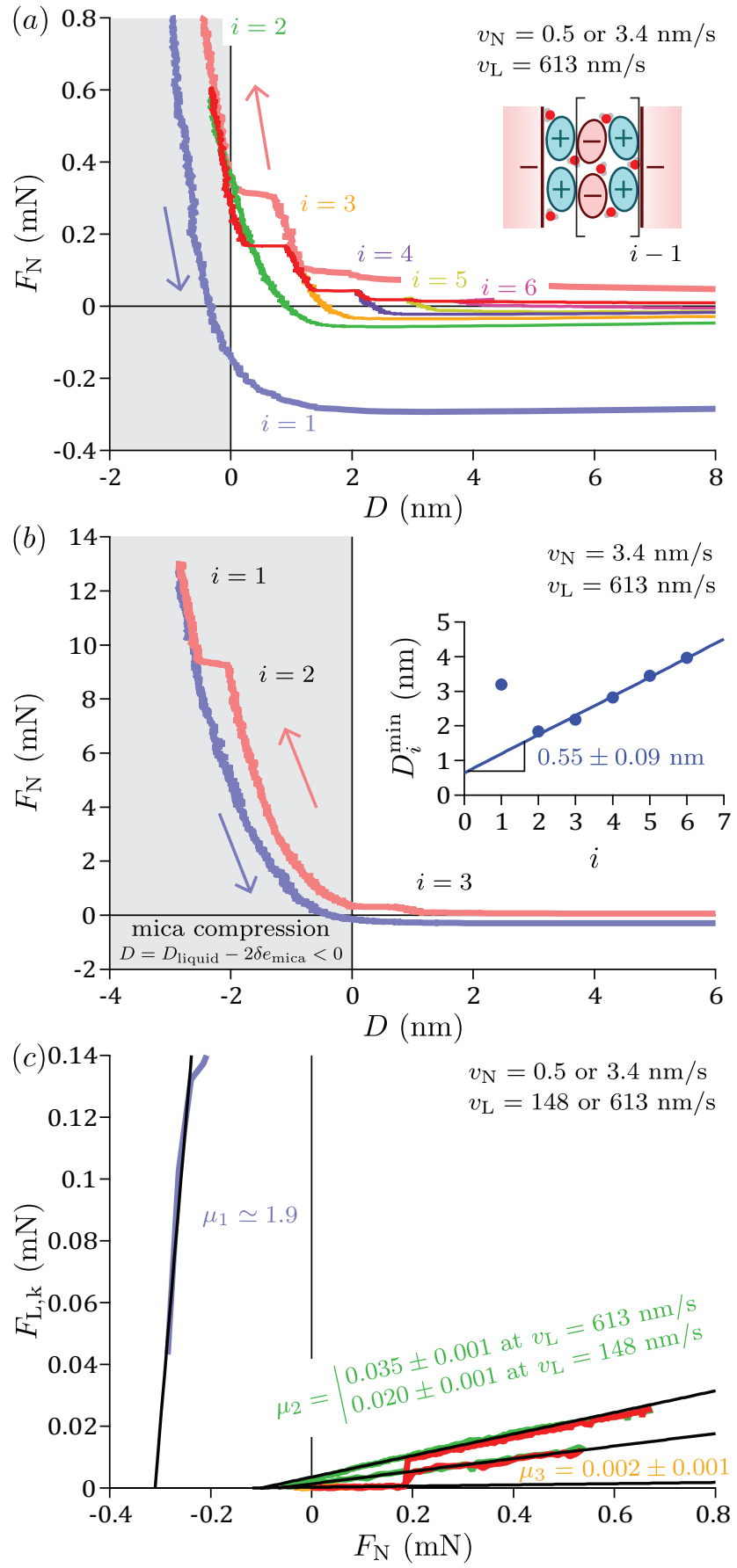

Fig. 5 Measurements for wet $\left[\mathrm{C}_{4} \mathrm{C}_{1}\right.$ Pyrr] $\left[N T f_{2}\right](R=1.45 \mathrm{~cm})$. (a) Normal ${ }_{574}$ force profile when moving the top surface normally with the piezoelectric tube at $v_{\mathrm{N}}=0.5 \mathrm{~nm} / \mathrm{s}$ or with the stepper motor at $v_{\mathrm{N}}=3.4 \mathrm{~nm} / \mathrm{s}$ (faded red and faded blue) and laterally at $v_{\mathrm{L}}=652 \mathrm{~nm} / \mathrm{s}$, showing structuring ${ }^{576}$ with 6 distinguishable layers labeled by $i$. For clarity, only the two full577 approaches are shown (in red for the piezoelectric tube, in faded red for the stepper motor), together with retractions from layers $i=1$ (in578 faded blue), $i=2$ (in green), $i=3$ (in orange), $i=4$ (in purple), $i=5_{579}$ (in yellow), $i=6$ (in pink). Inset: proposed structure of alternating layers of cations and anions with water traces. (b) Normal force profile when approaching or retracting the top surface with the stepper motor ${ }^{581}$ at $v_{\mathrm{N}}=3.4 \mathrm{~nm} / \mathrm{s}$. Inset: distances $D_{i}^{\mathrm{min}}$ at the points of minimum force, as ${ }^{582}$ a function of the layer index $i$, and corresponding linear fit (equation 2. 583 (c) Kinetic friction $F_{\mathrm{L}, \mathrm{k}}$ as a function of load $F_{\mathrm{N}}$. Straight lines are fits ${ }_{584}$ with the left-hand term of equation 4 with $\left\{\mu_{1} \sim 1.9, F_{1}^{\min } \sim-0.3 \mathrm{mN}\right\}$, $\left\{\mu_{2}=0.035 \pm 0.001, F_{2}^{\mathrm{min}}=-0.101 \pm 0.004 \mathrm{mN}\right\}$ and $\left\{\mu_{3}=0.002 \pm 0.001\right.$, $\left.F_{3}^{\min }=-0.12 \pm 0.03 \mathrm{mN}\right\}$. Friction clearly depends on lateral velocity in ${ }^{586}$ layer $i=2$, with $\left\{\mu_{2}=0.020 \pm 0.001, F_{2}^{\min }=-0.07 \pm 0.01 \mathrm{mN}\right\}$ at $v_{\mathrm{L}}=$ $148 \mathrm{~nm} / \mathrm{s}$. As retraction from $i=1$ has geen performed at a relatively

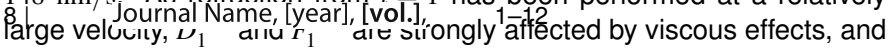
$\mu_{1}$ is estimated with only a few shearing periods.
532 .

\begin{abstract}
Qualitatively, such amplification of the ion density oscillations can be attributed to an enhanced dissociation of the potassium
\end{abstract} ions on the mica, leading to a larger surface charge.

Figure 5 (c) shows the kinetic friction force $F_{\mathrm{L}, \mathrm{k}}$ as a function of the load $F_{\mathrm{N}}$ for the wet ionic liquid. Again, the friction coefficient is indexed by the number of ions composing the liquid film, i.e friction is quantized. However, the lateral force is above the sensitivity limit for three layers, instead of two for the dry case. In layer $i=3$ (retraction branch in orange), the friction coefficient is $\mu_{1}=0.002 \pm 0.001$, i.e. the film composed of three cations layers plus two anions layers behaves as an extremely good superlubricant. In layer $i=2$ (retraction branch in green), the friction 
coefficient is $\mu_{2}=0.035 \pm 0.001$, i.e. the film composed of two 641 cations layers plus one anions layer is almost a superlubricant.642 For layer $i=1$ (retraction branch in faded blue), the friction co-643 efficient is $\mu_{3} \sim 1.9$, i.e. the film composed of a monolayer of $\mathrm{f}_{644}$ cations is a poor lubricant. Note that retraction from layer $i=1645$ has been performed at a relatively large velocity, so the value of $f_{646}$ $\mu_{1}$ is estimated with only a few shearing periods. Supplementary ${ }_{647}$ Figure 2 shows the friction-load relationship that has been mea-648 sured in a larger range of loads for layer $i=2$, by approaching the ${ }_{649}$ surfaces by discrete steps with the stepper motor. Similarly to the 650 dry case, a good fit can be achieved with equation 4 providing ${ }_{651}$ that the two contributions are included, the first proportional to652 the load and the second proportional to the contact area (with 653 $\left.\left\{\mu_{2}=0.0129 \pm 0.003, \sigma_{\mathrm{c}, 2}=56 \pm 2 \mathrm{kPa}, F_{2}^{\min }=-0.06 \mathrm{mN}\right\}\right) . \quad 654$

Overall, humidity is found to strongly increase the resistance of 655 the layers to be squeezed-out, without changing significantly their656 corresponding thicknesses and friction coefficients. Consequently, it leads to an extension of the range of loads in which the liquid behaves as a superlubricant. Such beneficial effect of water on the lubricating performances is extremely interesting for applica-657 tions, given that ionic liquids are hygroscopic and that lubricated 658 systems are never perfectly insulated from ambient moisture. $\quad 659$

\subsection{Kinetics aspects}

In this subsection, we consider the influence of the shearing ve- ${ }_{663}$ locity on the friction force. Supplementary Figure 5 shows the ${ }_{664}$ friction-load relationships measured in dry conditions at $v_{\mathrm{L}}={ }_{665}$ $652 \mathrm{~nm} / \mathrm{s}$ and $v_{\mathrm{L}}=67.9 \mathrm{~nm} / \mathrm{s}$. No clear trend is found within ${ }_{666}$ the experimental errors, whether in layer $i=1$ or in layer $i=2 ._{667}$ Figure 5(c) shows the friction-load relationships measured in wet ${ }_{668}$ conditions at $v_{\mathrm{L}}=613 \mathrm{~nm} / \mathrm{s}$ and $v_{\mathrm{L}}=148 \mathrm{~nm} / \mathrm{s}$. In layer $i=3, \mathrm{no}_{669}$ clear trend is found within the experimental errors, and layer $i=1_{670}$ was explored at only one shearing velocity. In layer $i=2$, how- ${ }_{671}$ ever, the friction clearly depends on the shearing velocity. More $_{672}$ precisely, the kinetic friction force goes to zero at the same adhe- ${ }_{673}$ sion minimum in both cases, but with a friction coefficient that ${ }_{674}$ is larger with the largest shearing velocity. These observations ${ }_{675}$ are consistent with previous SFB experiments performed with the ${ }_{676}$ same ionic liquid in our group, showing that in dry conditions ${ }_{677}$ the kinetic friction is independent of the shearing velocity in the ${ }_{678}$ range $v_{\mathrm{L}} \in[200 ; 1000] \mathrm{nm} / \mathrm{s}$, whatever the layer considered 15 . Our ${ }_{679}$ findings are also comparable with previous colloidal probe AFM experiments performed with protic ionic liquids (ethylammonium nitrate (EAN), propylammonium nitrate (PAN), ethylammonium formate (EAF), etc.) between a silica sphere $(R \sim 10 \mu \mathrm{m})$ and $\mathrm{a}_{680}$ mica surface, reporting on an increase of the friction coefficient ${ }_{681}$ with the shearing velocity in the range $v_{\mathrm{L}} \in[5000 ; 40000] \mathrm{nm} / \mathrm{s}$, for ${ }_{682}$ some particular film compositions ${ }^{13|14| 16}$. However, it is not clear ${ }_{683}$ why a dependence of the shearing velocity on the friction force is ${ }_{684}$ found or not, depending on the physico-chemical system and the ${ }_{685}$ layer considered.

To investigate this dynamics quantitatively, we have sheared687 the liquid under constant conditions in the normal direction, 688 exploring two decades of lateral velocities. Figure 6(a) shows689 the lateral force $F_{\mathrm{L}}$ as a function of the lateral displacement $x_{\mathrm{L} 690}$ when shearing wet $\left[\mathrm{C}_{4} \mathrm{C}_{1}\right.$ Pyrr $]\left[\mathrm{NTf}_{2}\right]$ at different velocities $v_{\mathrm{L}} \in$ $\{32 ; 128 ; 639 ; 1918 ; 3197\} \mathrm{nm} / \mathrm{s}$ (with same displacement range), at fixed load $F_{\mathrm{N}}=2.79 \mathrm{mN}$, distance $D=-1.05 \mathrm{~nm}$ (where $\left.D=D_{\text {liquid }}-2 \delta e_{\text {mica }}<0\right)$ and contact radius $a=12.86 \mu \mathrm{m}$ in layer $i=2$. A liquid-like friction behavior is obtained for all the friction loops, but with a kinetic friction force that increases monotonically with the the shearing velocity. Finally, Figure 6(b) shows the kinetic friction force $F_{\mathrm{L}, \mathrm{k}}$ as a function of the lateral velocity $v_{\mathrm{L}}$, in lin-log representation (Supplementary Figures 6(a) and 6(b) show the same data, respectively in lin-lin and log-log representations). The dynamics is strongly non-linear, and is interpreted with different models of friction kinetics in the following.

In friction experiments between smooth surfaces, dynamics is generally found to be thermally-activated, i.e. obeying an Arrhenius law of the form:

$$
F=F_{0} \ln \frac{v}{v_{0}} .
$$

Qualitatively, such thermally-activated dynamics is associated with the picture of molecules that must overcome energy barriers in order to pass each other, with the external force inducing a potential biais and with the temperature allowing for the crossing of non-zero barriers. It has been observed for dry friction (between Langmuir-Blodgett films with a SFA ${ }^{66}$, between a $\mathrm{NaCl}$ surface and a silicon tip with an $\mathrm{AFM}^{[67}$ ), as well as for lubricated friction in the boundary regime (between mica surfaces across apolar liquids or aqueous electrolytes with a SFA 68169 , between mica surface and silicon colloid across protic ionic liquids with a colloidal probe AFM $\left.{ }^{13}[14] 16\right)$. We have fitted our data with equation 5 (red curve in Figure 6(b)), giving $\left\{F_{0}=(23 \pm 4) \cdot 10^{-3} \mathrm{mN}\right.$, $\left.v_{0}=18 \pm 10 \mathrm{~nm} / \mathrm{s}\right\}$. Clearly, an Arrhenius law does not provide a satisfactory fit of the dynamics measured over two decades of velocities in the range $v_{\mathrm{L}} \in[30 ; 3000] \mathrm{nm} / \mathrm{s}$, which exhibits a significant curvature in a lin-log representation. This is in contrast with the previous colloidal probe AFM studies of friction across ionic liquids $13|14| 16$, showing a dynamics compatible with an Arrhenius law over one decade of velocities in the range $v_{\mathrm{L}} \in[5000 ; 40000] \mathrm{nm} / \mathrm{s}$. A modified Arrhenius law has been proposed, in the case where the potential biais induced by the external force is so large that the energy barrier almost disappears (i.e. at the vicinity of the spinodal) $70-72$ :

$$
F=F_{\mathrm{c}}-\Delta F\left(\ln \frac{v_{\mathrm{c}}}{v}\right)^{2 / 3} .
$$

Our data have been fitted with this model (green curve in Figure 6(b)), giving $\left\{F_{\mathrm{c}}=0.13 \pm 0.02 \mathrm{mN}, v_{\mathrm{c}}=(3.4 \pm 1.5) \cdot 10^{3} \mathrm{~nm} / \mathrm{s}\right.$, $\left.\Delta F=(36 \pm 7) \cdot 10^{-3} \mathrm{mN}\right\}$. It better reproduces the curvature of the data, and predicts that the spinodal transition is reached just at the top of the explored range of lateral velocities. However, several experimental, numerical and theoretical works in the literature propose to describe the lubricated friction dynamics by means of a shear-thinning rheology with an effective viscosity that decreases as $v_{\mathrm{L}}{ }^{-2 / 3}$, or equivalently a friction force that increases as $v_{\mathrm{L}} \mathrm{L}^{1 / 373-78}$. This can be written as an empirical power-law of the form: 

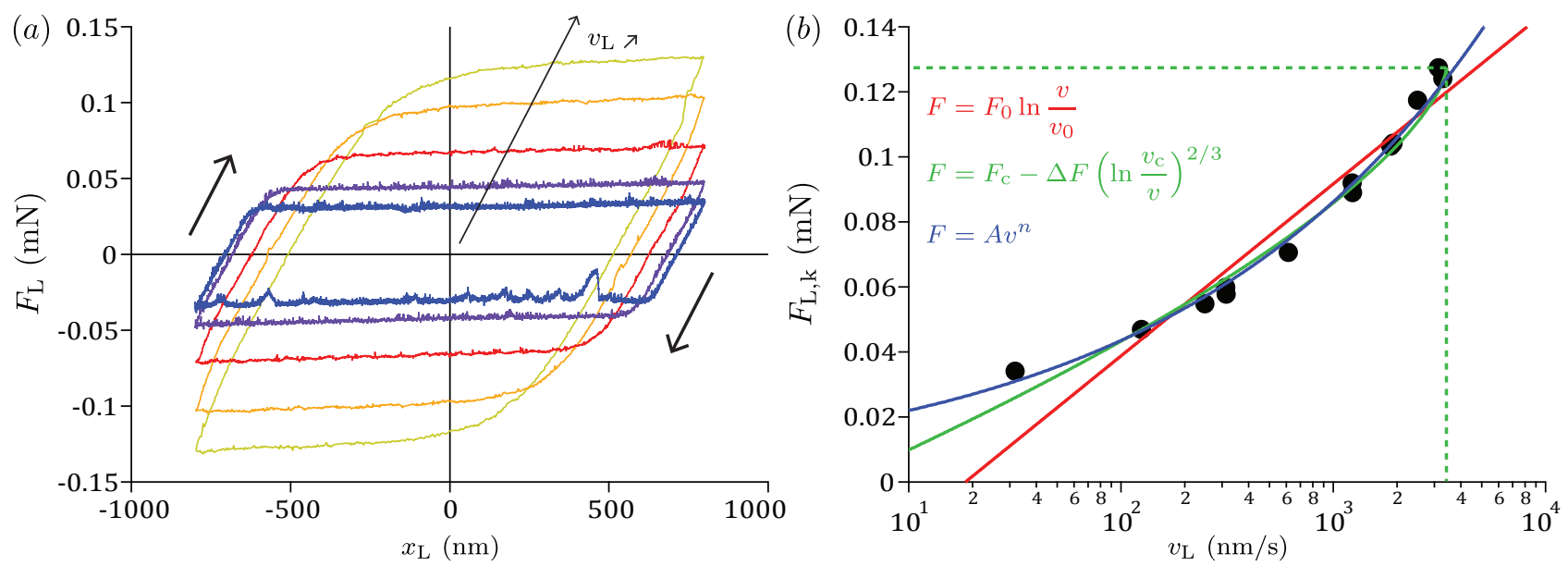

Fig. 6 Measurements for wet $\left[\mathrm{C}_{4} \mathrm{C}_{1}\right.$ Pyrr] $\left[\mathrm{NTf}_{2}\right](R=1.45 \mathrm{~cm})$, at fixed load $F_{\mathrm{N}}=2.79 \mathrm{mN}$, distance $D=-1.05 \mathrm{~nm}\left(\right.$ where $D=D_{\text {liquid }}-2 \delta e_{\text {mica }}<$ 0 ) and contact radius $a=12.86 \mu \mathrm{m}$ in layer $i=2$. (a) Lateral force $F_{\mathrm{L}}$ as a function of lateral displacement $x_{\mathrm{L}}$, for different lateral velocities $v_{\mathrm{L}} \in$ $\{32 ; 128 ; 639 ; 1918 ; 3197\} \mathrm{nm} / \mathrm{s}$ respectively in blue, purple, red, orange and yellow. The bumps on the signals, particularly visible for the blue curve, are due to external vibrations that are not totally suppressed by the damping elements of the SFB. (b) Kinetic friction $F_{\mathrm{L}, \mathrm{k}}$ as a function of lateral velocity $v_{\mathrm{L}}$, in lin-log representation. The red curve is a fit with equation 5 giving $\left\{F_{0}=(23 \pm 4) \cdot 10^{-3} \mathrm{mN}, v_{0}=18 \pm 10 \mathrm{~nm} / \mathrm{s}\right\}$. The green curve is a fit with equation 6 giving $\left\{F_{\mathrm{c}}=0.13 \pm 0.02 \mathrm{mN}, v_{\mathrm{c}}=(3.4 \pm 1.5) \cdot 10^{3} \mathrm{~nm} / \mathrm{s}, \Delta F=(36 \pm 7) \cdot 10^{-3} \mathrm{mN}\right\}$. The blue curve is a fit with equation 7 giving $n=0.30 \pm 0.02$.

$$
F=A v^{n},
$$

This model also fits reasonably our data (blue curve in Fig-724 ure 6(b)), with an exponent $n=0.30 \pm 0.02$ close to the reported ${ }_{725}$ value of $1 / 3$. Therefore, these measurements of the friction force ${ }_{726}$ over two decades of shearing velocities allow us to unambigu- 727 ously reject a description of the friction kinetics by an Arrhenius ${ }_{728}$ law, but not to discriminate between the modified Arrhenius law and the empirical power-law.

\section{Conclusions}

In this paper, we have presented proof-of-concept experiments for ${ }^{732}$ a new methodology to measure friction in the boundary lubrica- ${ }^{733}$ tion regime with a SFB. By applying simultaneous normal and lateral motions to the surfaces, the friction-load relationship can be ${ }^{734}$ measured more precisely, comprehensively and rapidly. The qual ${ }^{735}$ ity achieved opens the way to more quantitative investigations to ${ }^{736}$ relate friction, load, contact area, adhesion and shearing velocity, ${ }^{737}$ while the efficiency and the versatility of the method allow for ef ${ }^{-738}$ ficient probing of various physico-chemical systems. Using ionic ${ }^{739}$ liquids as a proof-of-concept, we have measured the phenomenon ${ }^{740}$ of quantized friction with an unprecedented resolution. Contrary to the existing studies in the area, we have found (i) a liquid-like ${ }^{741}$ friction behavior; (ii) a variation of the kinetic friction force with ${ }^{742}$ the applied load that is not simply linear, but can be quantita- ${ }^{743}$ tively described by two additive contributions proportional to the ${ }^{744}$ load and to the contact area; (iii) a dynamics over two decades ${ }^{745}$ of shearing velocities that does not obey a simple Arrhenius law, appealing for more sophisticated models of friction kinetics. Fur- ${ }^{746}$ thermore, we have observed that humidity can improve the lubri-747 cation performances of ionic liquid, by increasing the resistance of the layers to be squeezed-out and so extending the range of ${ }^{748}$ loads in which the liquid behaves as a superlubricant.

The results presented in this study raise a number of questions,750 listed below, that would require dedicated experimental investigations.

- Does the increase of mica surface charge with humidity explain the amplification of the ion density oscillation? This aspect could be specifically addressed by performing measurements with conductive surfaces, which surface potential can be controlled externally 28799, 81 .

- Can the relative orientation of the mica surfaces induce a transition from a solid-like to a liquid-like friction behavior also for ionic liquids? This hypothesis could be verified by measuring the friction behavior while varying systematically the twist angle between the mica surfaces.

- Should friction kinetics across ionic liquids be described by a thermally-activated process, or by a shear-thinning rheology, or another approach? The different models could be discriminated by exploring the dynamics over a wider range of shearing velocities to identify or not a spinodal transition, and by performing friction measurements at different temperatures.

- Is the variability on the lateral force measurement when changing the contact spot correlated to the presence of large domains of uniform orientation on the surfaces? This scenario could be tested by combining X-ray scattering and friction measurements in a modified SFA/SFB $40|82| 83$.

\section{Conflicts of interest}

There are no conflicts to declare.

\section{Acknowledgements}

S.P. and R.L. are supported by The Leverhulme Trust (RPG2015-328) and the ERC (under Starting Grant No. 676861, 
LIQUISWITCH). R.L. is supported by the EPA Cephalosporin Ju-804 nior Research Fellowship and Linacre College (University of Ox-805 ford).

\section{References}

1 F. P. Bowden and D. Tabor, The Friction and Lubrication of 809 Solids, Oxford University Press, 1950.

2 Fundamentals of Friction and Wear on the Nanoscale (Second811 Edition), ed. E. Gnecco and E. Meyer, Springer, 2015.

3 R. Lhermerout, C. Diederichs and S. Perkin, Lubricants, 2018,813 6, 1-12.

4 R. G. Horn, D. F. Evans and B. W. Ninham, J. Phys. Chem.,815 1988, 92, 3531-3537.

5 R. Atkin and G. G. Warr, J. Phys. Chem. C, 2007, 111, 5162-817 5168.

6 I. Bou-Malham and L. Bureau, Soft Matter, 2010, 6, 4062-819 4065.

7 S. Perkin, T. Albrecht and J. Klein, Phys. Chem. Chem. Phys., 821 2010, 12, 1243-1247.

8 K. Ueno, M. Kasuya, M. Watanabe, M. Mizukami and K. Kuri-823 hara, Phys. Chem. Chem. Phys., 2010, 12, 4066-4071. 824

9 X. Zhang, Y.-X. Zhong, J.-W. Yan, Y.-Z. Su, M. Zhang and B.-W.825 Mao, Chem. Commun., 2012, 48, 582-584.

10 J. Hoth, F. Hausen, M. H. Müser and R. Bennewitz, J. Phys. 827 Condens. Matter, 2014, 26, 284110.

11 H.-W. Cheng, P. Stock, B. Moeremans, T. Baimpos, X. Banquy,829 F. U. Renner and M. Valtiner, Adv. Mater. Interfaces, 2015, 2, 1500159-n/a.

12 L. Garcia, L. Jacquot, E. Charlaix and B. Cross, Faraday Dis-832 cuss., 2017, 206, 443-457.

13 O. Werzer, E. D. Cranston, G. G. Warr, R. Atkin and M. W. 834 Rutland, Phys. Chem. Chem. Phys., 2012, 14, 5147-5152.

14 A. Elbourne, J. Sweeney, G. B. Webber, E. J. Wanless, G. G.836 Warr, M. W. Rutland and R. Atkin, Chem. Commun., 2013, 49,837 6797-6799.

838

15 A. M. Smith, K. R. J. Lovelock, N. N. Gosvami, T. Welton and ${ }_{839}$ S. Perkin, Phys. Chem. Chem. Phys., 2013, 15, 15317-15320. 840

16 J. Sweeney, G. B. Webber, M. W. Rutland and R. Atkin, Phys. 841 Chem. Chem. Phys., 2014, 16, 16651-16658.

17 A. M. Smith, M. A. Parkes and S. Perkin, J. Phys. Chem. Lett.,843 2014, 5, 4032-4037.

844

18 N. Hjalmarsson, R. Atkin and M. W. Rutland, Phys. Chem. 845 Chem. Phys., 2016, 18, 9232-9239.

19 J. N. Israelachvili, Intermolecular and Surface Forces (Third ${ }_{847}$ Edition), Academic Press, 2011.

20 J. Klein and E. Kumacheva, J. Chem. Phys., 1998, 108, 6996-849 7009.

21 S. Perkin, L. Chai, N. Kampf, U. Raviv, W. Briscoe, I. Dunlop, 851 S. Titmuss, M. Seo, E. Kumacheva and J. Klein, Langmuir, 852 2006, 22, 6142-6152.

22 R. Lhermerout and S. Perkin, Phys. Rev. Fluids, 2018, 3,854 014201.

23 R. Lhermerout and S. Perkin, (to be published).

24 C. J. Rao, K. A. Venkatesan, B. Tata, K. Nagarajan, T. Srini- vasan and P. Vasudeva Rao, Radiat. Phys. Chem., 2011, 80, $643-649$.

25 R. M. Espinosa-Marzal, A. Arcifa, A. Rossi and N. D. Spencer, J. Phys. Chem. C, 2014, 118, 6491-6503.

26 J. N. Israelachvili, J. Colloid Interface Sci., 1973, 44, 259 272.

27 K. A. Schwenzfeier, A. Erbe, P. Bilotto, M. Lengauer, C. Merola, H.-W. Cheng, L. L. E. Mears and M. Valtiner, Rev. Sci. Instrum., 2019, 90, 043908.

28 M. A. Gebbie, M. Valtiner, X. Banquy, E. T. Fox, W. A. Henderson and J. N. Israelachvili, PNAS, 2013, 110, 9674-9679.

29 M. A. Gebbie, H. A. Dobbs, M. Valtiner and J. N. Israelachvili, PNAS, 2015, 112, 7432-7437.

30 A. M. Smith, A. A. Lee and S. Perkin, J. Phys. Chem. Lett., 2016, 7, 2157-2163.

31 N. Hjalmarsson, R. Atkin and M. W. Rutland, Chem. Commun., 2017, 53, 647-650.

32 J. Comtet, A. Nigues, V. Kaiser, B. Coasne, L. Bocquet and A. Siria, Nat. Mater., 2017, 16, 634-639.

33 A. A. Lee, C. S. Perez-Martinez, A. M. Smith and S. Perkin, Faraday Discuss., 2017, 199, 239-259.

34 A. A. Lee, C. S. Perez-Martinez, A. M. Smith and S. Perkin, Phys. Rev. Lett., 2017, 119, 026002.

35 A. Crespo, D. Mazuyer, N. Morgado, A. Tonck, J.-M. Georges and J. Cayer-Barrioz, Tribol. Lett., 2017, 65, 138.

36 R. Lhermerout, C. Diederichs, S. Sinha, K. Porfyrakis and S. Perkin, J. Phys. Chem. B, 2019, 123, 310-316.

37 M. L. Gee, P. M. McGuiggan, J. N. Israelachvili and A. M. Homola, J. Chem. Phys., 1990, 93, 1895-1906.

$38 \mathrm{H}$. Yoshizawa, P. McGuiggan and J. Israelachvili, Science, 1993, 259, 1305-1308.

39 S. Yamada and J. Israelachvili, J. Phys. Chem. B, 1998, 102, 234-244.

40 Y. Golan, A. Martin-Herranz, Y. Li, C. R. Safinya and J. Israelachvili, Phys. Rev. Lett., 2001, 86, 1263-1266.

41 C. Drummond, N. Alcantar and J. Israelachvili, Phys. Rev. E, 2002, 66, 011705.

42 R. M. Espinosa-Marzal, A. Arcifa, A. Rossi and N. D. Spencer, J. Phys. Chem. Lett., 2014, 5, 179-184.

43 J. Gao, W. D. Luedtke and U. Landman, J. Phys. Chem. B, 1998, 102, 5033-5037.

44 A. Socoliuc, E. Gnecco, S. Maier, O. Pfeiffer, A. Baratoff, R. Bennewitz and E. Meyer, Science, 2006, 313, 207-210.

45 P. A. Johnson, H. Savage, M. Knuth, J. Gomberg and C. Marone, Nature, 2008, 451, 57.

46 R. Capozza, A. Vanossi, A. Vezzani and S. Zapperi, Phys. Rev. Lett., 2009, 103, 085502.

47 F. Giacco, E. Lippiello and M. P. Ciamarra, Phys. Rev. E, 2012 , 86, 016110.

48 H. Lastakowski, J.-C. Géminard and V. Vidal, Sci. Rep., 2015, 5, 13455 .

49 B. V. Derjaguin, V. M. Muller and Y. P. Toporov, J. Colloid Interface Sci., 1975, 53, $314-326$. 
50 R. G. Horn, J. N. Israelachvili and F. Pribac, J. Colloid Interface ${ }_{910}$ Sci., 1987, 115, 480 - 492.

51 D. Maugis, J. Colloid Interface Sci., 1992, 150, 243 - 269. 912

52 D. S. Grierson, E. E. Flater and R. W. Carpick, J. Adhes. Sci. 913 Technol., 2005, 19, 291-311.

53 A. M. Smith, A. A. Lee and S. Perkin, Phys. Rev. Lett., 2017,915 118, 096002.

916

54 R. Hayes, S. Z. El Abedin and R. Atkin, J. Phys. Chem. B, 2009,917 113, 7049-7052.

55 B. V. Derjaguin, Wear, 1988, 128, 19 - 27.

56 E. Kumacheva and J. Klein, 7022.

57 A. Berman, C. Drummond and J. Israelachvili, Tribol. Lett., 1998, 4, 95.

58 D. Gourdon and J. N. Israelachvili, Phys. Rev. E, 2003, 68, 021602.

59 A. M. Homola, J. N. Israelachvili, M. L. Gee and P. M. McGuiggan, J. Tribol., 1989, 111, 675 - 682.

60 A. M. Homola, J. N. Israelachvili, P. M. McGuiggan and M. L. Gee, Wear, 1990, 136, $65-83$.

61 R. W. Carpick, N. Agraït, D. F. Ogletree and M. Salmeron, Langmuir, 1996, 12, 3334-3340.

62 G. Bogdanovic, F. Tiberg and M. W. Rutland, Langmuir, 2001, 17, 5911-5916.

63 M. Lessel, P. Loskill, F. Hausen, N. N. Gosvami, R. Bennewitz and K. Jacobs, Phys. Rev. Lett., 2013, 111, 035502.

64 J. N. Israelachvili, Y.-L. Chen and H. Yoshizawa, J. Adhes. Sci. Technol., 1994, 8, 1231-1249.

65 O. Y. Fajardo, F. Bresme, A. A. Kornyshev and M. Urbakh, ACS Nano, 2017, 11, 6825-6831.

66 B. J. Briscoe, D. C. B. Evans and D. Tabor, Proc. R. Soc. A, 1982, 380, 389-407.

67 E. Gnecco, R. Bennewitz, T. Gyalog, C. Loppacher, M. Bammerlin, E. Meyer and H.-J. Güntherodt, Phys. Rev. Lett., 2000, 84, 1172-1175.

68 M. He, A. Szuchmacher Blum, G. Overney and R. M. Overney, Phys. Rev. Lett., 2002, 88, 154302.

69 L. Ma, A. Gaisinskaya-Kipnis, N. Kampf and J. Klein, Nat. Commun., 2015, 6,.

70 Y. Sang, M. Dubé and M. Grant, Phys. Rev. Lett., 2001, 87, 174301.

71 E. Riedo, E. Gnecco, R. Bennewitz, E. Meyer and H. Brune, Phys. Rev. Lett., 2003, 91, 084502.

72 P. Reimann and M. Evstigneev, New J. Phys., 2005, 7, 25-25.

73 H.-W. Hu, G. A. Carson and S. Granick, Phys. Rev. Lett., 1991, 66, 2758-2761.

74 P. A. Thompson, G. S. Grest and M. O. Robbins, Phys. Rev. Lett., 1992, 68, 3448-3451.

75 M. Urbakh, L. Daikhin and J. Klafter, Phys. Rev. E, 1995, 51, 2137-2141.

76 A. Brodsky, Int. J. Mod. Phys. A, 1998, 12, 167-175.

77 S. T. Cui, C. McCabe, P. T. Cummings and H. D. Cochran, J. Chem. Phys., 2003, 118, 8941-8944.
78 M. Otsuki, J. Phys. Soc. Jpn., 2008, 77, 054002.

79 J. Sweeney, F. Hausen, R. Hayes, G. B. Webber, F. Endres, M. W. Rutland, R. Bennewitz and R. Atkin, Phys. Rev. Lett., 2012, 109, 155502.

80 R. Tivony and J. Klein, Faraday Discuss., 2017, 199, 261-277.

81 C. D. van Engers, M. Balabajew, A. Southam and S. Perkin, Rev. Sci. Instrum., 2018, 89, 123901.

82 S. H. Idziak, C. R. Safinya, R. S. Hill, K. E. Kraiser, M. Ruths, H. E. Warriner, S. Steinberg, K. S. Liang and J. N. Israelachvili, Science, 1994, 264, 1915-1918.

83 P. Kékicheff, J. Iss, P. Fontaine and A. Johner, Phys. Rev. Lett., 2018, 120, 118001. 